\title{
1
}

\section{Preliminaries and Proust}

This chapter presents a general outline of the psychoanalytical framework that forms the background of this study, followed by a reading of Beckett's dissertation on Proust. ${ }^{1}$ I try to minimize the inclusion of theoretical references and material in the main body of the text; this may allow for a more direct response to the flow of textual material. The concepts presented here provide a framework within which the reading takes place but, in the end, the textual material must speak for itself. If the reader feels something in Beckett appears more interesting or exciting, though there is doubt about a theoretical notion I may have used to achieve this effect, I will have accomplished what I am setting out to do.

One of the core arguments of this study is that Beckett's oeuvre is a manifestation of a narrative-self whose universe is organized by a dominant feeling of precarious connection to a primary, good internal presence. I read the work as a record of purely internal experience, and do not wish to make claims about the actuality of early deprivation or hostility on the part of external objects. Certainly, there are many ways of viewing this aspect of Beckett's work theoretically: a fundamental source of controversy among competing psychoanalytical theories is the weight to be placed on endowment versus nurturing. I suggest the broad emotional appeal of his work is due to its elaboration of an early experience that is part of all internal development: the sense of disconnection from an early source of external love and nurturing.

A fundamental background concept of this study is introjection, which I use to mean the process through which external experience becomes part of the self. This is a fluid, ongoing process, but in its most basic form during early life, it involves the manner in which the emerging, nascent self begins to take into itself experiences of others, of the world, and of external relationships. In the earliest states of mind, there is a blurring between self and other, and boundaries shift and 
dissolve. A major focus of this study is the earliest, most fundamental sense of contact with a good mother, which I tend to view as a primary introjection. I follow Klein in assuming that the primary act of the nascent self is the introjection of a good internal object, around which the self becomes integrated, through feeling loved and supported against whatever hostile, depriving experiences (internal or external) may beset it. In the very earliest stages of life, a central focus of Beckett's work, there are alterations in the cohesiveness of the self, as it integrates and disintegrates. ${ }^{2}$ These alterations are connected to the fragility of the internal sense of a good, enduring other, and the self depends on the actual appearance of the external good object. Simply put, as the infant feels a sense of terror, for whatever reason (cold, hunger, internal rage or nascent depression) it requires a containing object to allow it to begin to integrate such experience. The containment becomes, along with the object that contains, an enduring part of the self that allows for a feeling of vibrant, secure living. Thus, the continual presence of a good other allows this process to develop. Here we can see the relevance to Beckett, as, for example, when Watt begins to disintegrate when he is not in the actual presence of Knott, who acts for him as a wished for mothercontainer. We can look at Beckett's work in this way: as an exploration of the very early internal experience of disconnection from this primary object, which is fundamental in creating an enduring sense of self.

In trying to examine the internal experiences of such disconnection, I highlight certain imagery, symbols and other manifestations in the text. Of course, these are selective, but I hope they are not exclusionary. For example, in Chapter 2, there is an exploration of Murphy's 'theft' of tea from a waitress, who I suggest acts as an internally felt mother; in Chapter Five, I suggest the narrator of 'The End' expresses certain core feelings about himself (and about his primary object) in his defecation into his boat/womb, feelings elaborated in a statement by Klein:

The phantasized onslaughts on the mother follow two main lines: one is the predominantly oral impulse to suck dry, bite up, scoop out and rob the mother's body of its good contents. The other line of attack derives from the anal and urethral impulses and implies expelling dangerous substances (excrements) out of the self and into the mother. (Klein, 1988b: 44)

There are surely other ways of reading the examples I have just given; my use of the theory is an attempt to demonstrate something about internal experience. In this example, I feel that Klein's description of the 
fantasies of rage, and its enactment in the robbing and soiling of the mother, are related in some way to the internal experience of the narrative-self as manifested in the text.

\section{The narrative-self}

When my twin daughters were about four months old, my mother came to visit us. One evening, around midnight, I wandered into our living room, and found my mother sitting in the near darkness, with one of the twins in her arms, their faces close. Neither of them took any notice of me, they were in a world of their own. My daughter was smiling, gurgling sounds came from her mouth, to which my mother responded 'Are you telling me stories? Tell me some stories!' They continued on, my daughter mouthing sounds, clearly in response to loving replies, and questions, from her grandmother.

This scene is central to the following study. The internal world of the infant is its first story - at the beginning of life, this world is a preverbal, archaic, unconscious. It is the mother's role, as a primary auditor, to recognize, to hear, to make sense of this world. This relationship is taken into the child, its stories/world flourish as it develops. To feel secure in the world, with a vibrancy and love of life, requires a sense of a loving, primary listener. These early moments of contact are primal fictions, primal truths, moments of primary-process thinking that eventually elaborate into the complexities of cultural and social life. ${ }^{3}$ Within the mind, I see this core relationship as central to all creativity in life, it is a feeling that one is not alone, but heard and understood. It connects to the possibility of fiction-making as well, since the mother becomes the first part of the self that hears itself - she is the primal object of the internal narrative-self couple, in which the core, infantileself is the subject.

Not long after seeing my mother and daughter that evening, I happened on a neurological journal, in which there was an article about stuttering. Recent research was described: it is thought that there are disruptions in the part of the auditory cortex in which we hear ourselves speak. This notion seems central to Beckett: his work struggles to have part of itself (the primary mother/auditor) hear the infantile-self. The struggle is directed at the reparation of a primary gap within; the stuttering staccato of Not $I$ is a reflection of an early rupture within the mind, between an infant that is trying to be, and the self/mother that recognizes its being. 
I am reminded of a patient, a woman whose early life was filled with disruptions, with a constant feeling of not being seen by her mother as existing. She once told me how, as a child, she would play a game with herself. She would cut a large, cardboard box into a television, and then set a chair in front of it. She would enter the box and play-act a show, or a newscast, at times breaking off the fiction to leave the box. There, sitting in the chair, she would pretend to be her mother, appreciating the shows, laughing, seeing and listening. She struggled to forge a connection to an absent part of herself, through a dramatic re-enactment of the very failure that disrupted her drama. In Beckett, the fictional world acts in this way. It is an attempt to connect to the mother, telling stories about the rupture between the self and the listener, hoping to be heard, seen, made whole, so that it can go on, for the first time, together, alone.

Baker touches upon these concepts in his discussion of sections of 'From An Abandoned Work' (Baker, 1998: 16-17). There is an overtly Freudian, associative movement in Beckett's text 'my mother white ... enough of my mother for the moment ... [then] a white horse followed by a boy' (130). The sun moves from the mother to the horse, suggesting an obvious displacement of the narrator's feeling. The narrator comments that he has always been adversely affected by white things, but after seeing the white horse he flies into a terrible, 'blinding' rage, 'the white horse and then the rage, no connexion I suppose' (132). He feels finished with the story, there is 'nothing to add', the day/memory has been 'sucked white, like a rabbit, there is that word white again' (134). Baker writes of these passages:

[They are] an associative monologue about a split self, without full selfknowledge, pivoting around the mother. But even if the larger discourse behind this is psychoanalysis, the relationship is unstable. What role do such helpfully communicative pronouncements as 'the white horse and the white mother ... please read again my descriptions of these' (134) play in an art 'too proud for the farce of giving and receiving' ( $\mathrm{Dj} .141$ ) or an art that 'does not dabble in the clear, does not make clear?' ( $\mathrm{Dj}$. 94). (Baker, 1998: 16)

I suggest that the apparent undoing of meaning, primarily through the narrator's overt destabilization of psychoanalytical hermeneutics, is a defensive strategy to protect the self from mis-understanding, or from revelation in an abandoning, unheeding world. It is a dialogue between a core self and a not trusted, primary auditor/mother. The passages do 
suggest obvious 'analytical' meanings: a child's longing to be close to its mother, displaced onto a horse, against whom the child can then feel safe in raging against. However, in the undoing of these 'meanings', there is also a revelation of the genesis of the feelings. Like the narrator of Disjecta (i.e. 'Dj'), this narrator shuns the idea of sharing, there is nothing to add to the story, for us, for himself. The world is 'sucked white', a primal draining, though it is unclear whether this is purely aggressive, or is an attempt to keep something safe within the self, a wish for a primal nurturing (i.e. 'white' milk). Baker writes: 'the writer of From An Abandoned Work is already a reader, reading the inscriptions on his mind with a hopeless alienation from anything like a unified self. The text dramatizes the angry perplexity of a split subject reading his own psychic text ("there is that word white again") and failing to make sense of himself" (Baker, 1998: 17). I suggest the passages can make a terrible sense, not only to us, but also to the narrator. It is a plea for connection, by a self that is unifying, then fragmenting under the weight of non-recognition. The two aspects of the narrative-self are split; there is an un-bridged gap between infantile-self as creator, as storyteller, and the primal auditor/mother, the 'only white horse' that is remembered, un-remembered. As surrogate auditors, we are asked to read again, to hold the passage in our minds, to share the struggle of the self to connect and, in so doing, to connect with it. We are asked to understand that this art does make clear its ambivalence about sharing, about communication, and why there is such a terrible rage. It is a primal anger that rests behind a terrible fear of abject loneliness, in a world where a self is unseen, unheard, by a part of itself that is mother. In this way, Beckett's work also becomes 'about' the fundamental psychological nature of art. There is an ongoing oscillation in the artistic experience - as readers/viewers, we play the object, containing side of a virtual self, holding the text/self within our minds. Equally, our minds, our unconscious, infantile-selves are held by the virtual person, the virtual primal object, which the text becomes as we enter it.

I have said this study will be solely textual, and that I will only quote Beckett when he comments directly on his work. However, the one exception to this is a vignette from his early life that serves as central imagery for this study. Baker relates the vignette: 'Beckett told his friend Gottfried Buttner in 1967 that as a child he would pick up stones from the beach and carry them home, where he would build nests for them and put them in trees to protect them from the sea. He described his relationship to stone as "almost a love relationship, and associated it 
to death"' (Baker, 1998: 139). There are many references to stoniness in the oeuvre, and to suggest its connection to a Freudian death instinct, a wish for a return to inorganicity, is certainly fair. Along these lines, I once worked with a man who was deeply isolated from the world. $\mathrm{He}$ spent many long months as a youth in total seclusion, travelling in the far north on his own. As a child, there had been little connection to a loving mother, and he once related the following story. He was in a cabin and, as winter approached, he could see ice building up on the lake. The water was higher than usual that year, and as he walked along the shore he saw how the oncoming ice would soon encase the homes of the small animals that had built them, hoping for protection from the cold. These animals were the living, child parts of him, and though there is a description of the awesome power of natural decay, there is also a cry for helpful connection. This man lived in a world of frozen love, and he feared involvement with me, since the sea was his own destructiveness, as well as mine/the world's.

Beckett's autobiographical vignette suggests the core estrangement lying at the heart of the narrative-self, and its genesis in early feelings with the mother. The child protects the stones - reflective of his own internal, frozen, loveless state. The stones are also 'eggs', containing the hope for a re-emergence, a rebirth, as the child becomes a protecting maternal force in a world in which things that are born from a mothersea (as stones are) are destroyed by it. It is a primal love relationship, between a child and the mother from which it comes; the nest becomes a maternal mind in which the child places these symbolic aspects of himself. In fact, the stones can also be the mother, depicting the child's experience of her as cold, unfeeling, and a wish to protect her from his own rage, feeling himself, and her, slipping into an unthinking, oceanic nothingness. This is a story about the birth of Beckett's fiction and drama as well, the frozen, stone-selves are placed in a nest, a primal text, in which they remain safe, hidden, yet apparent. Buttner serves as a containing other for the feelings related in the vignette, repairing the gap to the extent a text is generated, and as the story/nest opens, he learns about Beckett's primal love. The condensation within the vignette is dense, as the child blurs into the mother, hiding from her nonrecognition of his need, building his own protective nest, and Beckett's written texts become nests in this way. Within them are aspects of an infantile-self with mother; in our reading we create a primal listener who will hear for the first time, moving away from destructiveness and hiding, into a sharing of early life. 


\section{The schizoid dilemma}

The work of Harry Guntrip on schizoid experience informs this study, since I will be looking closely at the experience of a loving connection between the self and the primary object. ${ }^{4}$ Guntrip felt that the desire to connect in loving relationships with other persons is the fundamental driving force of early mental life: 'the infant's first need is to love and be loved [and the] first object relationship is organized around this need. If the infant's need to love is rejected, it experiences the most painful emotional state: the feeling that its love is unacceptable' (Guntrip, 1968: 36). This is an important aspect of Beckett's world: the sense that one is unlovable and therefore will not be loved. There are a wide number of possible reactions to this experience, and many are found in the oeuvre: Murphy's sense of self-sufficiency, the disdain felt by the narrator of the Nouvelles for children and their happily dependent state, the imagery of, and desire to return to, a pre-object state, and feelings of rage and anger, often suppressed out of fear of damaging the needed love object. Guntrip formulated the basic schizoid dilemma as the inability to "be in a relationship with another person nor out of it, without in various ways risking the loss of both his object and himself' (Guntrip, 1968: 36). Such a dynamic is an enduring aspect of Beckett's fiction, from Murphy's declarations to Celia to similar effect, the tramps' waiting for a figure they desperately feel they need, to the later texts where a relationship is maintained with a primary internal object (that is felt to be unloving) by the use of fictional fantasies as a means of displacing and hiding feelings of rage and sadness. To some degree, failures in early relating are part of all human experience, and it is this aspect of mental life that we can examine in Beckett's work. Few of us have had our fathers murdered by an uncle who then sleeps with our mother, but we can connect to Hamlet's internal states because such primary experiences are part of our early fantasy life, and become part of the substrate of our ongoing adult experience.

Guntrips's theory of the regressed ego illuminates the dominant psychological constellation of the oeuvre. Greenberg and Mitchell write that it is:

constituted by a profound sense of helplessness and hopelessness. The depriving experiences with real others have produced a fear of and antipathy towards life so intense and pervasive that this central portion of the ego has renounced all others, external and internal, real and imaginary; it has withdrawn into an isolated, objectless state $[\ldots$ and $]$ 
seeks to return to the prenatal security of the womb, to await a rebirth into a more hospitable human environment. Thus, regression entails a flight and a longing for renewal. When the flight aspect is more prominent, the regression is experienced as a longing for death - relief from conflicted relations with external and internal objects. When the hope aspect is more prominent, the regression is experienced in connection with a return to the protection of the womb. (Greenberg and Mitchell, 1983: 211)

This ambivalence towards life is predominant within the narrative-self, manifested within the nature of the characters as 'real' people, the imagery, flow and associations of the text, and, in the later work, within the actual dynamic content of the narrator's words themselves. Murphy's longing for this objectless state, which contradicts his need for a deep and enduring love, Watt's hunger for containment and closeness to Knott, the images throughout the oeuvre of rooms that serve the dual function of protection and suffocation, these are all manifestations of this predominant self-state. The intense condensations of 'Fizzle 5' demonstrate this state quite poetically. It reveals a 'closed space' where 'all needed to be known for say is known' (236). It is a closure of the internal world to others, who are all needed, since all that is needed for the self to be is to be known by a loving other. But this is closed off in an internal void, as all (needed ideas, others) are already known: 'all needed [...] is known.' The ultimate journey is lonely, a world filled with the 'dead but not rotting' (237), as others, and the self, are neither alive nor dead, held hopefully/sadistically in this neither world. The road is 'just wide enough for two. On it no two ever meet' (237). The meeting that never occurs for Beckett, which is the source of so many failed endings, is a failed beginning, a failed meeting, a failed knowing between mother and child. Greenberg and Mitchell write further:

the helpless and terrified infantile ego, overwhelmed by unrequited longings and dread of abandonment, remains alive within the regressed ego, in the heart of the personality [...] In the face of the constant threat of depersonalization and disorganization, reasoned Guntrip, the ego continually struggles to remain attached to life. All mental life and involvement with others, real and imaginary, operates basically as a defence against regressive longing $[\ldots]$ the concept of the 'regressed ego' becomes a conceptual black hole, swallowing up everything else. Conflicted relations with others, and masochistic attachments to bad internal objects serve as the ego's protection against regression. Oral, anal, genital fantasies reflect 'a struggle ... to stay born and function in 
the world of differentiated object-relations as a separate ego'. (Greenberg and Mitchell, 1983: 212)

While I do not adhere to the concept that all fantasy or actual objectrelations function solely in this regard, I think the central point of this argument is useful for this study. The 'struggle to stay born' is perhaps not fully appreciated in many readings of Beckett, since the retreat from life, manifested in cynicism, philosophical posturing, and so forth, can mask it. Further, the attachments of the fiction - Murphy to an idealized Endon, Watt to Knott, the tramps to Godot, the late narrators to clearly internal persecutors - are understandable as a way of remaining alive, since this is felt to be better than nothing.

\section{Three positions}

A dominant assumption of this study is that Beckett's work often reflects experiences within the 'Paranoid Schizoid Position', postulated by Klein as the first organizational framework of the psyche. For Klein, 'the early ego largely lacks cohesion, and a tendency towards integration alternates with a tendency towards disintegration, a falling to bits' (Klein, 1988b: 4). Building on what she felt was a pure Freudian psychology, by implicating both the life and death instincts in the formation of the mind she added a distinctive feature to its genesis. For Klein, it was the way the ego saw itself that was of the utmost importance and the nature and content of fantasy life became the predominant building blocks of the mind. She believed the infant's only avenue to rid itself of deeply felt anxieties about annihilation, or 'falling to bits', was by projecting them outward into the world. There, depending upon the reception they received by a containing other, the internal fantasies about the self would be modified, becoming either ameliorated or even more terrifying.

I suggest part of the narrative function in Beckett's writing is a projection of such anxieties into the texts-as-fantasies; exploring such manifestations makes understandable the nature of these anxieties, aspects of their genesis, and the strategies used to control them. I do not view the Paranoid Schizoid Position as pathological in itself, but as a vital, ongoing part of human experience concomitant with the later Depressive Position. Klein believed that achieving this position, developed later in the child, was the most monumental task in human life, since it completed the human psyche. It involves an appreciation of 
the wholeness of the other, and a toleration of the attendant anxieties that one has destroyed or damaged the object through earlier feelings of anger. Ogden has written that it is only upon entry into the Depressive Position that a full integration of the self occurs, with a corresponding sense of 'I-ness' that allows for a full experience of the world. He has brought together a concept of an even earlier state of mind that he calls the 'Autistic Contiguous Position', which he defines as being:

associated with a specific mode of attributing meaning to experience in which raw sensory data are ordered by means of forming presymbolic connections between sensory impressions that come to constitute bounded surfaces. It is on these surfaces that the experience of self has its origins: 'The ego [the "I"] is first and foremost a bodily ego', i.e. the ego is ultimately derived from bodily sensations, chiefly those springing from the surface of the body. (Freud, Standard Edition, 19: 26, in Ogden, 1989: 49)

Supporting his concept with work from leading infant researchers, and the psychoanalytical notions of the 'second skin' and adhesive identification (discussed below), Ogden suggests such early experience of primal sensation is vital in creating the rudiments of the self. Of importance to this study is the fact that the primary maternal object plays the central role in these experiences through the contribution of her own body, her initiation and response to the child's bodily action and needs, and her innate understanding of their meanings. The importance of this position to the work of Beckett will be explored, since it is through this position that one develops a foundation of an internal 'home', a sense of 'I-ness' felt unconsciously as an actual 'place where one lives' (Winnicott, 1971). I see this search for a primary maternal home as a central struggle of the Beckettian narrative-self: an enduring search for a place of primary security and selfhood, in relation to a good, loving other felt to be an integral part of the self. The imagery (urns, garrets, houses), the searching for maternal objects and the difficulties inherent in these relations, and finally the relationship to the primary sensory qualities of language itself, all have an element of this profound, primary need for early contact. A vignette may integrate these concepts:

Mr. D was fully in the Paranoid Schizoid Position when we began our work together. He felt I was envious of him and that I, like the world, held him in contempt, or had hostile intentions towards him. He lived in a darkened room, much like Murphy's garret, and spent his days in 
abject loneliness. After a number of years of work, he had begun to experience me, in a very fragile way, as a caring, good mother. In one session, he hinted this process had begun. He evoked a Beckettian inner world, stating he was afraid to lose me, that I might die. He thought he would place me in an urn in the office where I could still be a helpful presence for him. Finally he spoke of 'mummifying' me, and then said 'But you are not a mummy at all. You are always there for me, not like Mommy. Oh, did you hear that!'

Here we are at the boundaries of the Paranoid Schizoid and Depressive Positions. The patient's placing me in an urn both kills me off (i.e. to protect himself against my envy and his fears of my retaliation for his envy towards me), but it also served a transitional, containing function through which he protected me, and kept me close. It further evokes a relationship, developed in the rest of the imagery. I became a 'mummy' that was dead, reflecting his experience of the internal primary object, but a 'mommy' that was also preserved and would not leave him. ${ }^{5}$ Finally, the split becomes clear, as he experiences me as a good, integrative force within himself, unlike the bad 'Mommy'. His calling out to me, to ensure that I heard him, enacts the primary constellation within the narrative-self - I became a primary auditor, containing, recognizing his internal world, its anxieties, and the creative, symbolic, efforts of the emerging-self to heal its primal wounds. The complex fluidity of this sort of imagery, as well as the fluctuations in the experience of self, other, and self-with-other, will be explored in this study.

To maintain a sense of bodily and psychic integration, a person with a feeling of rupture in primary contact will engage in certain activities, many of which are reminiscent of Beckett. For example, Ogden lists: rhythmic muscular activities like bicycle-riding or walking, eating, rocking, (sometimes in a rocking chair), riding buses or subways and maintaining or perfecting a system of numbers or geometrical shapes (Ogden, 1989: 70). Throughout the oeuvre, there is a persistent, determined attempt to hold the self together against disintegration-anxieties in these ways; in the later work, it can be argued that the process of writing/speaking begins to serve this function more directly. It is my view that all of Beckett's work is deeply concerned with maintaining a coherent selfhood, and that this is primarily predicated on struggles within the earliest positions of mental life that are the foundations of experience. The late play ... but the clouds ... demonstrates some of these experiences. There is a lone, male figure on stage, and his (disembodied) 
voice provides a commentary. This figure is an internal part of the self, and the piece reflects a primary experience, within the narrative-self, of early relations with a maternal figure. The male voice says:

Then crouching there, in my little sanctum, in the dark, where none could see me, I began to beg, of her, to appear, to me [...] For had she never once appeared, all that time, would I have, could I have, gone on begging, all that time? Not just vanished within my little sanctum and busied myself with nothing? Until the time came, with break of day, to issue forth again, shed robe and skull, resume my hat and greatcoat, and issue forth again, to walk the roads. (260)

This is the earliest part of the emerging-self, disconnected from a primary feeling of the mother, in a hidden part of the internal world. There has been some connection, allowing for the feeling that 'begging' is possible, since without any connection there would be no possibility of any experience at all. There are four possibilities regarding the relationship between the male figure and the woman: that she appears but vanishes 'in the same breath' (evoking a comparison to the play Breath), which allows for no experience of contact. Secondly, she lingers 'with those unseeing eyes I so begged when alive to look at me' (260). This allows for a more enduring sense of connection between an emerging-self and a mother, but one who is experienced as neither firmly established nor interested. It echoes a failure of primary recognition of the self, an experience this study will trace through Beckett's work. The third case has the female visage appear on the stage and speak 'inaudibly': '... clouds ... but the clouds of the sky ...' (261). This is the closest that the emerging-self can come to an integrated contact to the mother, and it explains the adaptations that are made by the figure, since the fourth case, the commonest, is the one that dominates internal experience:

case nought $[\ldots]$ in the proportion say of nine hundred and ninety-nine to one, or nine hundred and ninety-eight to two, when I begged in vain, deep down into the dead of night, until I wearied, and ceased, and busied myself with something else, more ... rewarding, such as ... such as ... cube roots for example, or with nothing, busied myself with nothing, that MINE, until the time came, with break of day, to issue forth again, void my little sanctum [...] to walk the roads. [Pause.] The back roads. (261-2)

The internal adaptation to the experience or non-experience of the mother's love is appropriately called 'case nought' as the maternal 
figure approaches the unavailability of many that precede it in the oeuvre (e.g. Knott, Godot, Endon), a primal 'case' that precedes all experience. A slippage begins, into the autistic space Ogden describes, as the self struggles to maintain coherence, though there is a hesitancy before finally acquiescing to the more 'rewarding' obsession of the 'cube-roots'. There is also a retreat towards nothingness, but one that still must connect to a nascent experience of otherness, and one that is possessed ('MINE'), for this maintains a living connection until another 'issuing forth'. ${ }^{6}$ This figure, like so many before him, will leave an 'unspeakable home' of internal loneliness, and wander as a shadow in the world, walking to maintain a physicality that contains the self. It is of special importance that we are given the qualifier - 'the back roads' for without an internal sense of connection to a good mother, this figure feels undeserving of authentic contact and, like so many other Beckettian characters, wanders on the margins of the world. The final words of the piece are spoken by the male voice, which repeats the female's words, appearing to connect to what might be an early, fragmented memory of the mother. Thus, this aspect of self forms a tenuous identification with the mother, but this voice also fades, abandoning the figure to begin yet another 'issuing forth' off this internal stage, in search of a complete connection. This piece embodies much that is central to this study: the primary modes of coping with internal maternal unavailability, a sense of enclosure that reflects the deadness of the inner world, the experience of the core, emergent self as both an internal, depleted character and as an observing part of the narrative-self, and the nascent sense of hope reflected in the selfprotection and wandering, an intention to 'go on'.

\section{Projective identification and containment}

Another central concept within this reading is projective identification. This is a complex, debated idea within contemporary psychoanalytical thought, and I will not attempt to do it justice in the following brief exposition. ${ }^{7}$ For purposes of this study I use the term to mean the manner in which a cohesive self (or a self that is striving towards cohesion) unconsciously experiences aspects of itself as being within another consciousness (though it may also be within a cultural object, an inanimate object, and so forth). The self that places (projects) parts of itself into another maintains a strong, unconscious connection to those parts, even when they are experienced as other. In an object- 
relational reading, one could argue this occurs in all aspects of fiction: the characters and imagery of Beckett are no more aspects of an underlying self than any other writer. However, I suggest that within his writing this early process, by which the self attempts to defend itself against anxiety, to maintain a connection with another, or to control another (for example, the 'puppets' of Murphy) is exposed to a degree and with a clarity not found elsewhere. Beckett's work is about that which makes fiction, and authentic life, possible - the primal projective texts/identifications with the mother/auditor.

Another closely related psychoanalytical concept that forms a central piece of this study is containment. Hinshelwood writes that 'the notion of 'containing' [...] derives from Klein's original description of projective identification in which one person in some sense contains a part of another. This has given rise to a theory of development based on the emotional contact of infant with mother and, by extension, a theory of the psychoanalytical contact' (Hinshelwood, 1991: 246). Essentially, the concept of containment suggests a primary relationship between one person and another. The embryonic self requires the mother to accept aspects of its internal world that for one reason or another are experienced as distressing. Thus, Rosenfeld writes about a patient who 'showed that he had projected his damaged self containing the destroyed world, not only into other patients, but into me, and had changed me in this way. But instead of becoming relieved by this projection he became more anxious, because he was afraid of what I was then putting back into him, whereupon his introjective processes became severely disturbed' (Rosenfeld, 1952: 80-1). In other words, the patient's internal world (the fundamental universe of self and others that reflect his total experience) was felt to threaten his own selfcohesion. It was necessary to attribute aspects of this universe (in this case a 'damaged self') to Rosenfeld. The patient's continued anxiety stemmed from the fact that without an understanding acceptance and interaction from Rosenfeld, there remained a fear that this damaged experience would be returned to him in an even more dangerous incarnation. This meant the patient became even more unable to take things in from the world, since he feared that what he had tried to rid himself of (bad internal feelings and experiences) would come back to haunt him. By understanding the patient's terror and his need to rid himself of these bad aspects of his inner life, and returning them with a non-hostile, calm acceptance, Rosenfeld maintained a contact with the man that allowed for mutative change. 
It is in the work of Bion that these ideas reached their earliest mature form. He began to connect these concepts to very early experiences between the child and its mother, experiences in which a child's most fundamental annihilation anxieties need to be accepted and transfigured by his most important other:

The analytic situation built up in my mind a sense of witnessing an extremely early scene. I felt that the patient had witnessed in infancy a mother who dutifully responded to the infant's emotional displays. The dutiful response had in it an element of the impatient 'I don't know what's the matter with the child.' My deduction was that in order to understand what the child wanted the mother should have treated the infant's cry as more than a demand for her presence. From the infant's point of view she should have taken into her, and thus experienced, the fear that the child was dying. It was this fear that the child could not contain. He strove to split it off together with the part of the personality in which it lay and project it into the mother. (Bion, 1967: 103-4)

Again, it is important to stress this is not necessarily a pathological process, but a fundamental early interaction between an infant and its mother. Because of the infant's early sense of fragmentation and powerful fantasy life, there is not necessarily any reasonable failure on the part of the mother. Thus, Hanna Segal would write:

When an infant has an intolerable anxiety, he deals with it by projecting it into the mother. The mother's response is to acknowledge the anxiety and do whatever is necessary to relieve the infant's distress. The infant's perception is that $[\ldots]$ the [mother] was capable of containing it and dealing with it. He also introjects an object capable of containing and dealing with anxiety [which then becomes part of the self, as an aspect of the internal world]. The containment of anxiety by an external object capable of understanding is a beginning of mental stability. This mental stability may be disrupted by two sources. The mother may be unable to bear the infant's projected anxiety and he may introject an experience of even greater terror than the one he projected. It may also be disrupted by excessive destructive omnipotence of the infant's phantasy [i.e. its inability to accept the need for contact with another who could be helpful]. (Segal, 1981: 134-5)

The 'container' is not limited to the psychoanalyst or mother; anyone able to listen to, and tolerate, such primary anxieties can function in this way (Langs, 1978). I suggest that apart from the manner in which certain characters in Beckett (e.g. Endon, Knott, Godot) are sought out to provide this function, the fictional process itself can provide it. Later 
Beckettian narrators use the creation of a fictional universe more explicitly as a means of containment. In the early work, there is often a sense of containment in symbols or imagery, as rooms, houses, hospitals, and so forth, provide this function; there is also a manner in which words themselves offer a containing function. In Bion's description of the failure of words to contain, we get an eerie echo of an experience perhaps most clearly presented in Not I. Thus, Hinshelwood writes about a 'man who stammers so that the words which should contain his emotions become engulfed and squeezed by the force of the emotion into a stammer or babble. The word is in this sense a container affected and disrupted by the emotion it is supposed to contain' (Hinshelwood, 1991: 250). In this sense, the Auditor in Not I is an overwhelmed, internal mother-container, who cannot process the sudden eruption of repressed feeling that 'she' verbalizes as a nascent part of the self.

\section{Catastrophe}

Beckett's work reveals a constant struggle to maintain contact with a good internal object, a contact that allows a nascent self to avoid the feelings of disintegration and annihilation. A search for the core anxiety of humanity dominates psychoanalytical history. Freud felt the early danger situation varied with the stage of development: the loss of the breast, the loss of love and ultimately the threat of castration were central to his thought. Klein's work with young children convinced her the predominant and most central anxiety was that of personal annihilation, or a complete, catastrophic destruction of the self and its psychic universe. This view was consistent with her belief in the dominance of the death instinct in human life, especially at the earliest moments of existence, and she saw the threat of its overcoming the self as the predominant anxiety of human experience. Ernest Jones, Freud's close colleague, had written earlier about a notion of catastrophic loss, aphanisis, by which he meant the deprivation of all possible connection to pleasure, and therefore the loss of existence (Jones, 1927: 459-72). Such a catastrophe, a final loss of all internal objects, is the dominant threat experienced in Beckett's work. Some of the mechanisms by which the self protects itself from these anxieties (i.e. during states when it does not feel contained by a meaning-making mother) are through a sense of omnipotence (i.e. others are not needed as I am all powerful), projection (i.e. others are attacking me; the generally hostile world often seen in Beckett), idealization (another external object is 
perfect and will protect me; e.g. Murphy with Suk or Endon) and splitting (keeping good and bad internal objects separate). Many of these strategies manifest in the texts.

One consequence of this is the overwhelming influence the dread of annihilation can have on the human experience. Bion felt this threat was present throughout life, and that this spectre of a primal catastrophe haunted all movement within the psyche. He believed the creative process of the mind, in its broadest sense, involved an engagement with this sense of primary loss and catastrophe, since the dismantling fragmentation inherent in change threatens the internal sense of containment engendered by a certain set of beliefs. There is a constant movement throughout life between the fragmenting anxieties of annihilation of the Paranoid Schizoid Position, and the integrative aspects of the Depressive Position (Bion, 1963). Thus, he conceived of a non-pathological move back towards the Paranoid Schizoid Position, which he coupled with the idea that at times projective identification was normal, useful for communication and understanding. Such movement, between early annihilation anxieties and the anxieties inherent in accepting an integrated completeness of an idea or person (which is transitory), forms the basis of normal mental life. This touches upon those interpretations of Beckett's work that see it as primarily about the process of artistic creation, since movement between these mental positions, and the danger inherent in it, is the foundation of creativity. The collapse of the artistic world is the collapse of internal mental life, if imagination becomes dead for ever. If the retreat into earlier psychic spaces is tolerable due to the security of an internal universe of good others, then rebirth occurs, since imagination was only dead in fantasy.

Looking at the consequences of primal anxieties that result from early failures of containment elucidates aspects of the Beckettian universe. Pervasive throughout the work is a sort of 'nameless dread', a threatening, haunting fear of non-existence engendered either by abandonment or by a usurpation of the self. ${ }^{8}$ Bion developed the concept to describe a meaningless fear (or fear of meaninglessness) that besets the infant in a state where its primary anxieties are not contained by the mother. In these circumstances, the infant takes into the psyche, not a good mother able to understand and make chaos meaningful, but an object that destroys meaning (by being experienced as insane, or forcing the self to withdraw into insanity), and which abandons the self to a dangerous, meaningless world: 'In practice it means that the patient feels surrounded not so much by real objects, things-in-themselves, but 
by bizarre objects that are real only in that they are residues of thoughts and conceptions that have been stripped of their meaning and ejected' (Bion, 1962: 116). The narrative-self in Beckett struggles to survive this central difficulty, from Watt's travails with the unnamable 'pots' in the house of an uncontaining Knott-mother, to the tramps whose perceptions and memories become clouded in an increasingly meaningless world presided over by an uncontaining Godot-mother. Perhaps, the Unnamable most endures this dread (the title of the novel can equally refer to a state of being, i.e. an unnamable dread), struggling in abject isolation, save for a feeling of containing, within itself, what can be best described as 'an internal object that strips meaning [and gives rise to] a superego [i.e. a primary internally felt other, or group of others] that issues meaningless injunctions about behaviour' (Hinshelwood 1991: 354). In this light, the experience of a self that is 'neither' revolves around the meaninglessness inherent in an 'impenetrable self' and 'an impenetrable unself'. This is predicated by a failure of containment, by the otherness implicit in the world behind the perpetually closing doors of the short piece 'neither' (see below).

Winnicott provides an alternative model of early annihilation anxiety that is useful to this study. His notion of impingement focuses not so much on maternal abandonment per se, but on ruptures in the infant's illusory sense of omnipotent being. He felt the mother was required to support the infant's notion of independence, by providing basic needs in a timely fashion that allowed the infant to continue to believe it was autonomous, until such time that it could gently tolerate the reality of its actual vulnerability. Thus, Winnicott shifts the origin of the annihilation anxiety from a Kleinian internal object to actual external failure. My position will be to examine the work from an internal perspective, though within this it is possible to trace feelings of impingement. Thus, Watt's feeling of duty towards Knott, the tramps' 'requirement' to stay and wait for Godot, and the sense of internal, unnamed demands within the self of later narrators, can all be viewed as breakdowns in the development of an autonomous sense of self due to an experience of an internal other who does not allow for the development of self-esteem.

Winnicott also developed the notion of a primal catastrophe. In one of his last papers, he grapples with his own feelings about death, and describes the fear of annihilation or breakdown as the fear of a breakdown that has already been experienced. (Winnicott, 1973). Phillips elaborates on this: 
The death [Winnicott] describes [...] as having already happened is the psychic death of the infant, what he calls the 'primitive agony', of an excessive early deprivation that the infant can neither comprehend nor escape from. This intolerable absence of the mother was beyond the infant's capacity to assimilate. It was included as part of the infant's total life experience, but it could not be integrated, it had no place. Beyond a certain point [... the infant] could not hold his belief in his mother's existence alive in his mind [... These] events without context, they had merely happened $[\ldots]$ What was registered, unconsciously in Winnicott's view, was an interruption, a blanking out, an absence in the person's self-experience. [The Unconscious] is a place where deprivations are kept. (Phillips, 1988: 21-2)

It is this space, or non-space, that dominates the internal world of the Beckettian narrative-self. This study examines the experience of this non-experience, as it manifests in imagery and associations, and as it is structured within re-enactments of primal scenes of disconnected agony. These notions connect to the well-known story of Beckett's fascination with the lecture of Carl Jung, during which he described the case of a girl who was not 'fully born'. In his discussion with an actress playing May in Footfalls, Beckett stressed the need to understand that May was never 'born', but 'just began' (Knowlson and Pilling, 1979: 222). Beckett, like Winnicott, was preoccupied with a sense of not truly beginning, and perhaps this is why there are so many attempts to start again, to be born properly, as the fictional process mirrors the psychological. The convergence of Beckett's artistic exploration and the psychoanalytical approach I am developing is echoed in the statement of Phillips, that for Winnicott: 'One of the aims of psychoanalysis was to re-establish continuity with whatever constituted the patient's "personal beginning". At the end of his life Winnicott was preoccupied by the final experience he might be unable to have, and by understanding the earliest deprivations that could make people feel that they had not begun to exist' (Phillips, 1988: 22). These are the struggles of the narrative-self, whose greatest fear is not to be alive enough to die properly, as an autonomous, real presence in the world.

Following closely on the concept of containment is that of mirroring, which also forms part of the background approach of this study. In Winnicott's understanding, the baby sees itself when it looks at the mother:

What does the baby see when he or she looks at the mother's face? I am suggesting that, ordinarily, what the baby sees is himself or herself. In 
other words the mother is looking at the baby and what she looks like is related to what she sees there. All this is too easily taken for granted. I am asking that this which is naturally done well by mothers who are caring for their babies shall not be taken for granted. I can make my point by going straight to the case of the baby whose mother reflects her own mood, or worse still, the rigidity of her defences. (Winnicott, 1971: 112)

The infant receives from the mother something it has already given in its own look, and this will help to consolidate its own internal experience: 'The infant's first image of itself includes a connection with the mother; by the mother's look, the infant knows that it is seen' (Summers, 1994: 142, italics mine). There are a number of other conceptions of mirroring, but Winnicott's captures the essential point. ${ }^{9}$ Regardless of one's specific beliefs about what the mirroring, or in more recent terminology 'empathy' or 'attunement', achieves for the internal self-state of the child, there is the central fact of a recognition experienced as somehow real. When Murphy does not feel seen by Endon, when Krapp does not feel seen in the punt, and when Vladimir, in a near panic, asks the Boy whether he is seen, the important thing is the experience of recognition, and its implied effect on the development of a secure, stable internal world and sense of self. Certainly, different theories present divergent opinions on the results of such recognition and its failures, but all agree that it is a vital part of self-experience and growth. My major concern in using the concept is that it provides a general framework within which certain recurrent experiences, that are manifested in the texts, can be understood as reflecting a primary state of connection, or disconnection, from the mother during early experience. Winnicott also developed a concept related to mirroring, and this, too, informs this study. This is his notion of holding, or the means by which the mother anticipates and protects the child's emerging-self. For Winnicott, this included not only an appreciation of the continuity of physical dependency that occurs after birth, but also of the importance of psychic contact.

\section{An unspeakable home}

Another important element of very early experience related to containment, and which forms a foundational background to this study, is the nature of the function of skin and touch. In the early 1970s, Esther Bick began to use sophisticated techniques of infant observation to develop the concept of 'adhesive identification' (Bick, 1968, 1986). This related 
to the very earliest moments of the child's extra-uterine life, its experience of its first object (the mother), and the introjection of this object into the psyche. Bick found that in situations where there was some problem in connection between the infant and the mother there is a developmental difficulty in which the infant cannot project its experience because of the absence of a developing internal space. In essence, the self is in its most primal, unintegrated state, seeking a maternal object, through touch: 'Bick proposed the notion of a "psychic skin" which ideally serves to bind together the experiences or "parts" of the nascent self, on their way toward integration into a cohesive sense of self' (Mitriani, 1994: 67). This notion connects to Freud's concept of the primal ego as a bodily ego, a projection of surface. For Bick, the 'psychic skin' is dependent on a primal other, an undifferentiated object composed of "experiences of continuous interaction between a physically and emotionally "holding" and mentally "containing" mother, and the surface of the infant's body as a sensory organ' (Mitriani, 1994: 67). Bick hypothesized that 'later, identification with this [psychic skin] function of the object supercedes the unintegrated state and gives rise to the $[\mathrm{ph}]$ antasy of internal and external space $[\ldots$ and $]$ until the containing function has been introjected, the concept of space within the self cannot arise [and] construction of an [internal containing] object [... will be] impaired' (Bick, 1968: 484). Within Beckett, these are central experiences, which find expression in a constant search for otherness, and in endless retreats into the self. The search is primarily for a containing object, a primal mother, 'a light, a voice, a smell, or other sensual object - which can hold the attention [and hold] the personality together' (Bick, 1968: 484). It is often forgotten how important touch is to the creation of textual meaning. Children begin to understand the symbolic potential of letters through touch, by handling their little wooden letters and puzzles, by making their erratic little crayon markings and, finally, when sitting nestled in the lap of a loved one, by touching words in their story books. Letters/texts are the primal Beckettian shape that holds the world, and the self, together, as a sort of protomother, and ruptures in this first contact are evident throughout the oeuvre. Mitriani discusses a young female patient, for whom early maternal presence was fleeting, fading; she experienced her patient as trying to make meaning out of her mother's absence:

[She was an infant] who must have been continually obsessing about whether or not she had cried too loud or perhaps not loud enough. 
Maybe the pitch of her cry was too high or maybe too low. Maybe she should continue to cry out or perhaps she should stop at once, and if so, for how long? [She wondered] if mother was ill or asleep, or perhaps she had finally left forever. Was mother dead? Or was she? (Mitriani, 1994: 75).

This describes the feeling-state of non-recognition central to the Beckettian voice. The texts are not only an expression of this state, but serve to counterbalance it. As Mitriani writes of her patient: 'although [her] material was quite communicative, it became apparent that her ruminations were not really thoughts connected to experiences, but rather an agglomeration of words which provided a cocoon of sensation within which she could wrap her precarious self for protection' (Mitriani, 1994: 75).

Aspects of this very early sense of disconnection between the emerging-self and the mother are apparent in Beckett's work from the beginning. The failure to develop internal space, predicated on ruptures in this early connection to maternal touch, is evident in the pervasive sense of enclosure. This manifests in the smallness of rooms (e.g. in Murphy, the Trilogy), the condensation of space in How It Is, Endgame, and Waiting for Godot, and the compression reflected in the density and self-enclosure of the prose (beginning in Watt, and extending through Texts for Nothing, and the later short prose and short dramatic pieces). The complex, complete encirclement of internal space reaches its heights with the late stories (e.g. 'The Lost Ones'), and in dramatic pieces like Not I. The main point about this self-enclosure is its relation, in the very earliest instance, to a failing primary connection to the internal mother. There is a double quality and function to such enclosure, the British child psychotherapist Frances Tustin (1980) postulates 'autistic objects' which serve to protect the child from early experiences of rupture from the world that is mother. The Beckettian world, and its textual incarnation, is filled with barriers (rooms, clothes, and words) that serve both to protect the self from invasion by functioning as a carapace, and to prevent a leakage of the self into a boundless world.

In Beckett's late piece 'neither', one finds a highly condensed expression of these experiences:

To and fro in shadow from inner to outershadow

from impenetrable self to impenetrable unself by way of neither as between two lit refuges whose doors once neared gently close, once turned away from gently part again beckoned back and forth and turned away 
heedless of the way, intent on the one gleam or the other unheard footfalls only sound

till at last halt for good, absent from self and other

then no sound

then gently light unfading on that unheeded neither

unspeakable home

This is a highly condensed metaphor of very early experiences of primary disconnection. ${ }^{10}$ The wanderer of the piece can be seen as a core, emerging-self trapped in an enclosed space, between an unaccepting outer world and an undeveloping internal world, which are both felt to be shadowy and inhospitable. There is a sense of hostility or lack of interest in the self, as there appears to be an active sadism (or mechanical deadness): the doors open, seemingly beckoning the wandering self, only to close as it approaches. ${ }^{11}$ The notion of refuge within a place or behind a door is symbolic for containment within a maternal mind, or within a mental space in which such a presence is felt. This is often echoed, in Watt, for example, where the house of Knott is continually seen as a refuge. The 'unheeded' neither-self is not recognized, and unheard, and this forms the core of the difficulty as containment becomes impossible, leaving the emerging-self wandering in the inbetween world explored in Beckett's fiction. It is an 'unspeakable home' before words, before a sense of time, existing only on the margins of the earliest moments of life. It is 'unspeakeable' in its primal horror, a motherless space that should be the first home, the first place of welcome.

Meltzer developed these ideas of closed internal spaces and failures of early containment. He describes a child who 'tended to draw pictures of houses, in which there was a house on this side of the paper, and there was a house on the other side of the paper and when you held it up to the light, you saw that the doors were superimposed, you know, a kind of house where you open the front door and step out the back door at the same time' (Meltzer, 1975: 300). It is this collapse of space that we see in 'neither', as the houses, representative of internal and external worlds, collapse into a space in which Guntrip's 'regressed ego' struggles to move, balanced between complete withdrawal and a struggle to go on living. The wanderer in 'neither' moves within the space that is between the two sides of the picture; both sides are necessary for life, one side the inner house that is the internal world of the self, the other the world of living others that begins with an experience of the interiority of the mother. ${ }^{12}$ For this child, as for the Beckettian narrative-self, there is a condensation of this space into a 
near nothingness, a space it keeps from total collapse by its own creation of space, through fantasy and speech. There is something within this early experience of an absent mother, reflected in the adhesion of the child's drawings of houses, which suggests the need for containment within another. The houses also represent the child-with-mother, the buildings are symbolic of inner worlds that the child must glue together in order to maintain contact. There is something of this quality in the entangled, adhering relationships one finds in Beckett, from the attachment of the servants to Knott, to the tramps attachment to each other and to Godot, to the tight, airless representations of inner room/ worlds in the late fiction. Bick called one of the outcomes of this sort of experience a 'second-skin' formation by the infantile-self, a means of holding itself together when contact is uncertain: 'Disturbance of the primal skin function can lead to the development of a "second-skin" formation through which dependence on the object is replaced by a pseudo-independence, by the inappropriate use of certain mental functions, or perhaps innate talents, for the purpose of creating a substitute for this skin container' (Bick, 1968: 484). An example of a second-skin is the precocious development of speech, through which the child contains itself by the sound of its own voice, an important aspect of the Beckettian monologue. She also describes a certain muscular rigidity that contains and quiets sensation, something evident in a number of characters (e.g. the hero of the Nouvelles, Clov and Hamm) whose bodies are rigidified into postures that entrap, but also contain. There are many other examples of second skin functioning in Beckett: the jar that contains the Unnamable serves both to contain him and entrap him, and the many urns, rooms and enclosed dramatic spaces serve such a function for the narrative-self. ${ }^{13}$

Winnicott's notion of potential space is also germane to this discussion. Potential space has to do with an arena of imagination developed within the infant's mind through a loving connection to a patient, playful (and play-allowing) mother; potential or transitional space is one in which:

we are neither inside the world of dream and fantasy nor outside in the world of shared reality. We are in the paradoxical third place that partakes of both these places at once. So while the boundary between the 'me' and the 'not-me' is of fundamental importance in the attainment of integration, health and indeed sanity, the potential space, 'the place where we live', transcends this boundary. (Davis and Wallbridge, 1981: 160) 
This space is often enclosed within Beckett, and it is one into which the narrative-self struggles to emerge. Again, it is in the compressed inbetween place of 'neither', where genuine adventure or exploration is shut off, so that the journey of life becomes encased within the early states of mental being. Late stories demonstrate movement into this world of transitional space through their internal fiction-generating, as do later dramas such as Footfalls, in which a repressed character/part of a unified self struggles to create within a context of internal enclosure (i.e. within the play proper).

There are similarities between these concepts and the Winnicottian notion of the 'false self' (Winnicott, 1965: 148). Winnicott felt an experience of premature separation from a vital primary object engendered sensations of severe annihilation anxiety. To counter this overwhelming sense of internal fragmentation a false self develops, in which a set of personality characteristics emerge that are not authentic, but designed to conceal the lack of true being, and to allow for rudimentary acceptance by the world. The Beckettian world is filled with experiences of premature ruptures from important objects, and the sense of a false self floats throughout, from the mimicry of Watt and the hero of the Nouvelles, to the withdrawn compliance of the heroine of Not I and the struggles of the late narrators for identity and their sense of the usurpation of their authenticity. Bick also comments on another aspect of the false self phenomenon: 'the catastrophic anxiety of falling-into-space, and the dead end [which] haunts every demand for change and which engenders a deep conservatism, and a demand for sameness, stability and support' (Bick, 1986: 299). The anxiety about change, this love of sameness, is a familiar one in Beckett. However, the deadened 'dead end' is one the narrative-self refuses to accept, as it continues to create, to start again, hoping for a change that will bring primal contact.

\section{A lorn land}

The central thesis of this study is that Samuel Beckett's fictional/ dramatic universe is organized by an emerging-self attempting to maintain an enduring contact with a good primary object/mother, and that his writing explores the experience of this self, its genesis, defences, and reactions to failures of such contact. One of the characteristic features of the Paranoid Schizoid Position is a loss of contact with the most despairing, depressed parts of the self, since annihilation anxieties 
and feelings of rage dominate the internal world. Such withdrawn/ depressed parts of the self are often in relation to unconscious early fantasy figures, and often the relationship centres around primary feeding experiences that reflect the earliest ways in which one engages the world. Beckett's fiction/drama often displays a sense of primary self-disruption, in the imagery and expression of starvation and feeding. This suggests an emerging-self caught in a 'neither' world on the edge of life, struggling to love and to be loved.

The internal sense of security that allows the infant to engage the world in a productive, creative fashion begins to develop from the earliest moments of life. This development is intimately connected to the primary nursing situation the child enjoys with its mother, a composite of feelings of being nourished, held, kept warm and touched. It is through this experience that the child begins to develop a sense of trust in the possibility of love, and begins to expect, through the repair of inevitable frustrations, that an interaction with a non-hostile world is possible. This is why, at the core of the paranoid state, we often find experiences of disruptions in the feeding experience. Hardy's poem 'The Puzzled Game Birds' illustrates the dramatic paranoid shift that occurs when the birds realize they are being killed by those who have also loved and fed them:

They are not those that used to feed us When we were young - they cannot be These shapes that now bereave and bleed us?

They are not those who used to feed us, For did we then cry, they would heed us.

- If hearts can house such treachery

They are not those who used to feed us

When we were young - they cannot be! (Hardy, 1994: 31)

Here is the struggle to maintain a Depressive Position, which would allow the birds to accept the traumatic reality that they are, in fact, being killed by those whom they love, and who they feel have loved them. There is a sense of dissociation as the others become depersonalised 'shapes', and the deepest level of the birds' attachment centres around the mother's recognition of the needs of the infantile-self: the birds were heeded, and fed, when they cried. The splitting of whole objects remains intact to the end, as the birds maintain with ever more vigour that those who would feed and love the young cannot be the same as those who would now drain them of life. ${ }^{14}$ The birds' poetic 
statement reflects the internal experience of the infant who is confused ('puzzled'), terrorized, and raging at the world/mother for her absence or misattunement to his needs, and who feels that this is tantamount to her killing him, either directly or in retaliation for his own anger.

In another poem from this period, 'Winter in Durnover Field', Hardy elaborates the sense of hostility that is the centre of the paranoid state, and which hovers around the notion of a more generalized worldas-mother who withholds food from the infantile-self. Three birds walk under a grey sky, across a field in which recently sown wheat has frozen:

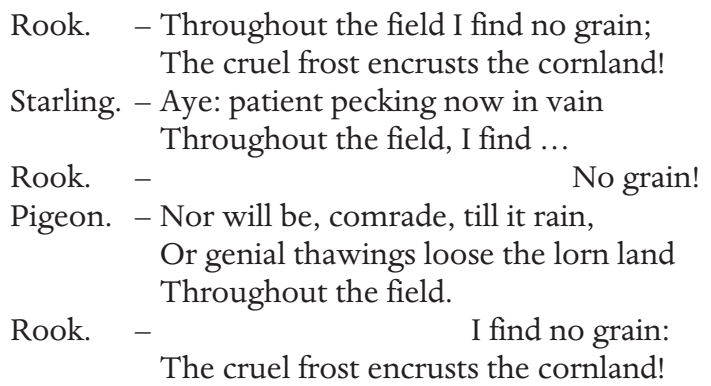

(Hardy, 1994: 31-2) $)^{15}$

Here, the birds are starved by the world, experienced as a barren, frozen place, a barren world/mother reminiscent of many Beckettian settings, from the world of mud in How It Is, the 'bog' and 'Cackon' country of Waiting for Godot, to the grey nothingness of Endgame. The voice of the Rook, with its constant refrain of 'no grain', reflects the deepest, most despairing part of the self, engaged with an 'encrusted', unavailable mother-'cornland' whom he feels is dead, starving him. The Pigeon's hopeful, and (perhaps) realistic, musings go unnoticed, as the Rook is stuck in a paranoid stance: the time is now, and now is always; I am hungry, and world/mother is dead to me. In 'Birds at Winter Nightfall', Hardy makes the mother more human: 'the flakes fly faster/the berries are all gone/Shutting indoors that crumb-outcaster we used to see upon the lawn.' (Hardy, 1994: 31). The nurturing mother remains unavailable, inside a house that represents an excluding maternal mind, and there appears to be an emotional, withholding agency on the part of the world. The primacy of dependence, in the face of such a harshly experienced world, is the centre of the mother-infant universe at the beginning of life, and is the beginning of love. It is within the early nursing situation that the central relational dynamics that organize the 
internal world are developed, and it is here that Beckett's fiction often elaborates the foundations of human emotional life. In his writing, these issues receive an intensive fictional investigation, with this sense of a depriving, uninterested world/mother forming a consistent internal background. This sense of disconnection is often expressed as a primary state of anxiety, depression, or paranoia, and there are numerous examples where this state is entwined with images of feeding or primary nurturing. The state that ensues will be a confused one, where boundaries are unclear, as the infantile-self is uncertain about the origins of the rage, loneliness, and anxiety that it feels. In Watt, the primal importance of words in Beckett becomes explicit, as their relation to early nurturing situation comes into focus. Watt's endless internal ruminations serve as autistic objects, protecting him from the frustrations, invasiveness of a hostile/ unavailable maternal world; they act as a 'second skin' that becomes a sensual and containing presence. As the narrator of 'Heard in the Dark 2' states: 'Simple sums you find a help in times of trouble. A haven ... [E]ven still in the timeless dark you find figures a comfort' (250-1).

One of the functions of the seemingly endless internal monologue created in some of Beckett's non-dramatic work, and in certain dramatic pieces, is to act as a nurturing, maternal containment. This protects the self, and re-creates (or creates for the first time) a 'haven' that approaches primary containment. It is within the enclosed monologues that the nature of the early ruptures can be found. Beckett alluded to these fundamental qualities of words while speaking to an actress who played May in Footfalls: 'Words are as food for this poor girl ... [T]hey are her best friends' (Asmus, 1986: 339). Words become primal nutrients for the narrative-self, allowing an ongoing engagement in a creativity that replaces, and strives for contact. In Beckett's work, the infantile-self struggles to engage the world, torn between a turning away from the mother/other, and an emergence into a realm of experience and risk. The opening words of 'The Image' condense this core experience of emergence/retreat poetically, and within the framework of an early nursing relationship with the world/mother: "The tongue gets clogged with mud only one remedy then pull it in and suck it swallow the mud or spit question to know whether it is nourishing' (165). This is the underlying image that dominates the internal world portrayed within the texts - a struggle between emergence and hiding, despair and hope, predicated on a sense that the world, being unknowable, may be as dangerous as it may be nurturing. 


\section{Proust}

In his dissertation on Proust, Beckett describes a constellation of experiences at the heart of the Paranoid Schizoid Position, and gives a hint as to their genesis. This section examines those aspects of his study relevant to this reading - in particular, the fundamental importance of a containing, maternal mind in organizing a cohesive, calm, internal world.

In Proust, Beckett writes of the bizarre, even inhuman quality of experience in what is clearly a primal state of mind: 'I would describe men, even at the risk of giving them the appearance of monstrous beings, as occupying in Time a much greater place [...] extended beyond measure, like giants plunged in the years, they touch at once those periods of their lives - separated by so many days - so far apart in time' (2). The experience of temporal self-continuity with a coherent, stable set of internal objects is inadequately achieved during the earliest moments of life, when the psyche struggles with cognitive immaturity and powerful physical needs. The 'monstrosity' that Beckett suggests to be part of mankind's natural endowment is just that: the fundamental connection to the world proceeds as a struggle to maintain wholeness (of others and the self), and to maintain a coherent sense of time and change. This passage describes the immense boundlessness of potential experience, which would overwhelm the self, were it not for primary maternal containment. In the Paranoid Schizoid Position, change is felt as inherently dangerous, since self-integration has not been achieved: 'There is no escape from yesterday because yesterday has deformed us, or been deformed by us [... it ] is within us, heavy and dangerous. We are not merely more weary because of yesterday, we are other, no longer what we were before the calamity of yesterday' (2-3). This equates the primary dangerousness of time and change to an attack on identity. In early states of experience, internal needs and desires that depend on a primary other for fulfillment can, when unfulfilled, cause serious disturbances in identity, and in the constancy of the object. The good mother, loving and helpful, disappears, replaced by a bad, withholding or absent mother. The sense of self is equally disrupted as internal calm becomes dominated by panic and rage. Since the mother holds the self together, making the infant continuous, this state disrupts complete connection to the world, which becomes terrifying in its inconsistency: 'The aspirations of yesterday were valid for yesterday's ego, not for to-day's. We are disappointed at the nullity of what we are 
pleased to call attainment. But what is attainment? The identification of the subject with the object of his desire. The subject has died - and perhaps many times - on the way' (3). This is an expression of experience within a Paranoid Schizoid state: there is a sense of depletion due to the constant struggle to maintain connection to a perfect object, a struggle engendered by inevitable fluctuations in early attunement between mother and infant. The universe seems populated by mysterious, unknowable others who arbitrarily attend to the self, along a spectrum ranging from loving to uninterested, withholding, and hostile. However, in successful early relationships, this struggle can lead to, not the death of the subject, but of otherless narcissism; the mother becomes as whole as the infantile-self that experiences her. Beckett goes on to consider:

a mobile subject before an ideal object, immutable and incorruptible [...] Exemption from intrinsic flux in a given object does not change the fact that it is the correlative of a subject that does not enjoy such immunity. The observer infects the observed with his own mobility [...] we are faced by the problem of an object whose mobility is not merely a function of the subject's, but independent and personal: two separate and immanent dynamisms related by no system of synchronisation. So that whatever the object, our thirst for possession is, by definition, insatiable. (6-7)

Again, this passage describes experience within the Paranoid Schizoid Position. There is the sense of an ideal object that can form a predominant, defensive constellation with the self, against the realities of change and frustration. Further, this object is somehow damaged ('infected') by the nature of the self and its demands. The impossibility of perfect 'synchronization' is dangerous, since in this primal state of mind dis-connection carries the weight and terror of eternity. There is a need for total possession of the mother, and it is this need for domination that is projected, creating a terrifying, engulfing world. It is not surprising that the primary sensation is of an 'insatiable' 'thirst'; the mother and the breast can never be adequately introjected in this state, since time fragments them into part-objects that are hated when they fail. Beckett's statement, that all that an 'I' can realize 'in Time [...] can only be possessed successively, by a series of partial annexations - and never integrally and at once', is a perfect description of experience in the Paranoid Schizoid Position.

It becomes increasingly clear that such experience is dominated, for Beckett, by considerations regarding the nature of love, seen as a 
powerful, complete incorporation of the other. The following reflects struggles within this primal state:

Even suppose that by one of those rare miracles of coincidence $[\ldots]$ realization takes place, that the object of desire $[\ldots]$ is achieved by the subject, then the congruence is so perfect $[\ldots]$ that the actual seeks the inevitable and, all conscious intellectual effort to reconstitute the invisible and unthinkable as a reality being fruitless, we are incapable of appreciating our joy by comparing it to our sorrow. (3-4)

These words describe another primal anxiety constantly explored in Beckett's writing. If, in these primary states of mind, the other becomes congruous with the self, there is a loss of potential and of growth, since there is a collapse into narcissistic otherlessness. The self, which can only be by existing in time, faces elimination, as 'aspiration' (i.e. psychic change and life) is destroyed, the world collapsing into a determinism founded by the primitive belief in omnipotence ('the actual seems inevitable'). The most fundamental need of the mind, to connect to a living other, remains unattained, since it demands frustration and misattunement. It is the mother who primarily modulates the possibility of change and surprise (i.e. the 'invisible and unthinkable') by placing herself just outside the infant's experience, but not so far as to be lost altogether. If the mother is absent, or if the infant does not allow her presence, the foundations of living feeling are destroyed, and no effort of the intellect can reconstitute them. One is neither alive nor dead, a grey, changeless world becomes predicated on the loss of feeling, as joy and sorrow become one.

In Proust, there is a glimpse of the type of primal relationship that generates such experience. The 'future' seems hopeful, the self is calm, 'smug' in its will to live until '[its] surface [is] broken by a date, by any temporal specification allowing us to measure the days that separate us from a menace' (5). Beckett gives examples: Swann's distressed fragmentation upon realizing he will be separated from Odette, and the narrator's panic, triggered by the realization Albertine is scheduled to be with her aunt the following evening. Of the genesis of these states of panic Beckett writes: 'the tacit understanding that the future can be controlled is destroyed' (6), reflecting the fractured disorganization of an infantile-self confronted with an inevitable failure to remain omnipotent. The urge to devour the world, to make it part of the self, conflicts with a need for the otherness that is life. In an attuned early environment, this experience is mitigated, mediated by the mother's 
love and patience, but for Beckett's Proust: 'No object prolonged in this temporal dimension tolerates possession, meaning by possession total possession, only to be achieved by the complete identification of object and subject' (4-5). Through enduring relations with a loving other, this statement, instead of evoking loss and defeat, could be read as a prerequisite for authentic living, and self-integration. Sense could begin to be made of the world, as the feeling that others are simply 'separate and immanent dynamisms related by no system of synchronization' diminishes through authentic contact (7). Again, there is a dual implication to the statement that 'the creation of the world [does] not take place once and for all time, but takes place every day' (8). Though change is necessary for life, it need not be catastrophic change in which all that comes before is forgotten or destroyed. It is through the endurance of the self, predicated on a good, stable set of early internal objects, that life becomes both continuous and surprising. Rather than the 'compromise between the individual and the environment' (7) being felt as a 'dull inviolability', it becomes a living, though sometimes confrontational, engagement with the whole world. For Beckett's Proust, the response to this situation becomes engagement with the world through habit, which in a dislocated experiential world is a 'generic term for the countless treaties concluded between the countless subjects that constitute the individual and their countless correlative objects' (8). Habit becomes the ultimate protector of the self, guarding against an endless series of shifting others. This situation is inalterable, since the 'periods of transition that separate consecutive adaptions (because no expedient of macabre transubstantiation can the gravesheets serve as the swaddling clothes) represent the perilous zones in the life of the individual, dangerous, precarious, painful, mysterious and fertile, when for a moment the boredom of living is replaced by the suffering of being' (8). A central, subjective sense of the narrative-self manifests here, as life becomes dull, devoid of genuine engagement and vitality. The despair is typically condensed; there is disappointment that life cannot be avoided, since one cannot be born into the grave-sheets, yet the life that remains retains the same futility. Moments of being without the mother, which in a healthy environment serve as times of internal structure building, here become filled with a vitality of danger, pain and mystery. However, there is no balance, these times are full of 'suffering', as if 'being' can mean nothing more than lonely isolation. There is no possibility of 'being alone in the presence of the mother', when the child is contained, secure within its mother's mind, feeling 
that securing recognition within itself so it can go on alone, yet not alone. Here the alternatives are suffering, akin to a form of disintegration anxiety, a loss of internal objects, or a bored engagement in life. This boredom seems to be a consequence of the intractable mutability of human engagement: in a world where others are constantly changing and unknowable, boredom serves a protective function, protecting the self from the severe trauma of an endless series of ruptured engagements. It also reflects the inability of the self to maintain an enduring experience of maternal containment; there is an endless sense of waiting for a mother who will make the self whole and life meaningful. Real engagements are condemned to be lifeless, as the ego or self becomes as a 'minister of dullness', a protective 'agent of security' (10):

When it ceases to perform that [security] function, when it is opposed by a phenomenon that it cannot reduce to the condition of a comfortable and familiar concept, when, in a word, it betrays its trust as a screen to spare its victim the spectacle of reality, it disappears, and the victim, now an ex-victim, is exposed to that reality - an exposure that has its advantages and disadvantages. It disappears - with a wailing and gnashing of teeth. The mortal microcosm cannot forgive the relative immortality of the macrocosm. The whisky bears a grudge against the decanter. (10)

The self is limited to its role in organizing reality into the 'comfortable and familiar', to protect the 'individual' from the 'spectacle' of reality; this ego-function is essentially a Freudian one. However, there is a sense this also entails a realization of maternal otherness, since the mother's unique personhood cannot be controlled, reduced through an omnipotent control. A sense of smallness haunts the nascent self, one evinced in 'grudging' anger at the mother's 'immortality', the containing 'decanter' whose mind must hold her growing child, allowing a gentle integration into the world. In Beckett, this situation is often reversed; the self often experiences the maternal mind as overly engulfing, unable to tolerate its need for both containment and separation.

Beckett's own illustrations from Proust elucidate the consequences and the nature of a self that is isolated, compliant, withdrawn from the beauty and danger of the world, and drugged by a life-draining habit. He describes Proust's narrator, on vacation with his grandmother, staying at the Grand Hotel (12-13), feeling 'feverish and exhausted', but unable to calm himself to sleep in the 'inferno of unfamiliar objects'. He is 'defensive', 'vigilant', 'taut', and as 'painfully incapable of relaxation 
as the tortured body of La Balue in his cage, where he could neither stand upright or sit down'. That Beckett chooses this scene is important, for within it lies the essential experience that organizes his oeuvre. In fact, the adjectives are appropriate to his own work: a world in which characters are defensive, vigilant, and taut, strangers in strange lands, often unable to sit (in welcome), or to stand (to leave). The world becomes a storm of 'sound and agony' that the Proustian narrator cannot quell, objects are threatening and violent, and he is amidst 'wild beasts'. His grandmother comes in, and 'comforts him', helping him prepare for sleep as if he were a child. She helps him to 'unbutton his boots', undress, and 'puts him to bed', and comes again in the night, when he needs her. In a sense, the narrator exists no more; he is fragmented and dissociated, and 'there is no room for his body' in the room. In his terror, he fills the space with an inner dread, creating a 'cavern' of monsters. In a very real way, this is reminiscent of early childhood terrors, in fantasy and dream, and it is not surprising that when the maternal figure comes to him, he is calmed again. Separate, alone, he suffers primary separation anxiety, and is incapable of reorganization without the mother. The experience brings to mind Bion's description of the 'bizarre objects' that occur when the self is fragmented, extruded into an unbounded world, becoming prey to a world filled with its own 'beasts': 'Each particle [of the self] is felt to consist of a real external object which is encapsulated in a piece of the personality that has engulfed it [...] The object, angered at being engulfed, swells up, so to speak, and suffuses and controls the piece of the personality that engulfs it: to that extent the particle is felt to have become a thing' (Bion, 1956: 344-6). Proust's narrator experiences such an internal disruption, entering the same state that threatens the narrative-self throughout the oeuvre, as he 'rids himself of the apparatus of conscious awareness of internal and external reality [achieving] a state which is felt to be neither alive nor dead' (Bion, 1956: 39). The arrival of a maternal object binds the chaos, allowing for the re-integration of a living self. A second vignette that Beckett chooses reinforces the importance of maternal presence; having telephoned his grandmother, the narrator hears her voice:

now for the first time, in all its purity and reality, so different from the voice $[\ldots]$ of her face that he does not recognize it as hers. It is a grievous voice, its fragility unmitigated and undisguised by the carefully arranged mask of her features, and this strange real voice is the measure of its owner's suffering. He hears it also as the symbol of her isolation, of their 
separation, as impalpable as a voice from the dead. The voice stops. His grandmother seems as irretrievably lost as Eurydice among the shades. Alone before the mouthpiece he calls her name in vain. Nothing can persuade him to remain at Doncieres. He must see his grandmother. $(14-15)$

The strangeness of the telephone-voice creates a dislocation in his experience of grandmother as an internal, living presence. Regardless of the woman's real feelings at that moment, the narrator experiences a disturbing disconnection from a primary maternal presence within himself, one that connects to the primal experiences of touch (i.e. the voice is 'impalpable'). This creates an internal deadness predicated on separation from an integrating, inner mother, to which he must reconnect by seeing the woman in person. A number of patients have had this experience with me during conversations on the telephone. Not being able to see me in person ruptured a primary sense of containment, creating an overwhelming panic, and a feeling that all goodness and love was lost. Beckett's understanding of the episode in the hotel elaborates on this: 'But this terror at the thought of separation - from Gilberte, from his parents, from himself - is dissipated in a greater terror, when he thinks that to the pain of separation will succeed indifference, that the privation will cease to be a privation $[\ldots]$ when not only the objects of his affection have vanished, but also that affection itself' (14, italics mine). This world is both terrifying and potentially beautiful. The only defence against separation anxiety becomes habit, but it is a lifekiller, since it destroys the hope that the individual might survive the terror and be able to organize the world. The will for authentic living is lost, 'an idle tale' suffocates the vibrant narrative of human life, as a far worse anxiety ensues. The individual loses not only the loved internal persons, but also the capacity to love, and to be loved. This is the ultimate catastrophe, the world becomes a dead world, as the self collapses into a defensive position that protects against the pain of separation. It is better than no world at all, however, and this place is home to the narrative-self, as it struggles to engage a loving other.

In this world, the self is fragmented, devitalized, either doomed by habit and intellectualization to a deadened existence or, alternatively forced to face a strange, de-realized world of terrifying loneliness and 'wild beasts'. It is a world without the possibility of hope, love has been stillborn, blocked by a fear of engulfing otherness, or by rage. Beckett's quoting of Proust suggests the inevitability of such a state: 'How have we the courage to wish to live, how can we make a movement to 
preserve ourselves from death, in a world where love is provoked by a lie and consists solely in the need of having our sufferings appeased by whatever being has made us suffer?' (38, italics mine). This is a world deprived of joy, of mutual attunement and sharing, it is a world of loneliness. Love becomes mere manipulation, an attempt to force the mother-as-contemporary figure to repair an early, basic fault, felt as a narcissistic wound. ${ }^{16}$ An awareness of this never-ending search, and the impossibility of filling the inner void, leaves the Proustian narrator disillusioned and suicidal, and Beckett is in close agreement with these feelings: 'Surely in the whole of literature there is no study of that desert of loneliness and recrimination that men call love posed and developed with such diabolical unscrupulousness' (38).

Love, for Proust (writes Beckett), is 'our demand for a whole' (39), a statement that lies at the heart of both men's work. For Proust, a remembering of the past is an attempt to create a more cohesive self, to repair a self ruptured and fragmented by the loss of an internal, maternal figure. In Beckett, there is an even more desperate attempt to hold a world together, when the basic ability to reach the world, to love, is lost within the earliest states of experience. Beckett's world teeters between a complete, final withdrawal in hopeless despair to an isolated, but safe, internal sanctuary, and a faint, almost imperceptible cry, to be born again, to go on, to a mother who this time will love, recognize, hear. For Proust, and for Beckett, others exist in discontinuity, 'And not only "I", but the many "I"s'. For any given Albertine there exists a correlative narrator, and no anachronism can put apart what Time has coupled' (43). This is the Paranoid Schizoid experience, as a sense of wholeness of self and other is eternally beyond reach. As the speaker of A Piece of Monologue states: 'No. No such thing as a whole' (260). Tottering on the edge of the Depressive Position, this speaker's world is fragmented, too. Things went wrong from the beginning of psychic birth - at the first 'suck' began the 'first fiasco', a primal sense of rupture in the nurturing, loving bond. The first steps, between mother and nanny, were felt as unaffectionate (the speaker was 'bandied about' between neither-doors), as life became a march from 'funeral to funeral', with a false self 'ghastly grinning' (265). Like Watt with the Knott-mother, the speaker wanders in darkness, unable to bring forth a sense of love, always 'almost' saying 'loved ones', but unable to tolerate the depressive anxiety, to integrate something that cannot be whole. The piece is full of imagery of primal connection: 'Birth. Parts lips and thrusts tongue between them. Tip of tongue. Feel soft touch of tongue 
on lips. Of lips on tongue. [...] Stare beyond through rift in dark to other dark. Further dark. [...] Nothing stirring' (268). This is a primal disconnection that begins with a failed psychic birth, reflecting the sensations of failing touch between the mouth and the breast, across a primary gap ('rift') to the mother's body and mind, as an uncontaining darkness envelops the internal world, as nothingness stirs, still. The inner world becomes a vast darkness full of 'ghosts': 'Ghost light. Ghost rooms. Ghost graves. Ghost ... he all but said ghost loved ones. Waiting on the rip word' (269). The 'ripping' that so kills the emerging-self, preventing wholeness from developing, is the tearing away from the mother's presence, from the touch of lips and breast, creating a gap in the self that leaves one's words meaningless and void. As well, there is a wish to tear oneself away from this dead, encasing feeling of primary failure, a wish aborted by the terror of premature separation. ${ }^{17}$ Like May, in Footfalls, this speaker has only one concern, one thing that is it all': there is 'never but the one matter', a need to repair an internal connection that leaves him wandering in a world where there are only ' $[t]$ he dead and gone. The dying and the going. From the word go' (269).

Without an enduring sense of maternal presence, of containment within a loving, recognizing maternal mind, there can be no enduring self. Proust's narrator seeks the mother in disparate figures, and failing to find her, attempts to hold himself together by searching in the past. The Beckettian narrative-self manifests this fragmented searching continuously through the oeuvre, as characters fight boredom and despair in a place where there is 'nothing to be done'. It is a search for an attuned, recognizing mother, who holds the primal self; it is a search that continues because 'one desires to be understood because one desires to be loved, and one desires to be loved because one loves' (46, italics mine). This is the motive for the search of Proust's narrator, and the motive behind the faint voice of Beckett that 'must go on'. Only in speaking can the narrative-self hope to be heard, to be understood, and fulfill its need to love, and be loved, by the part of itself it first touched in the mother. Love for Proust, and for Beckett, becomes a 'function of sadness', founded on inescapable isolation, rather than any enduring interrelatedness. Communication is impossible, to attempt to share oneself with another is a 'human vulgarity', or 'horribly comic, like the madness that holds a conversation with the furniture' (46). Others are unreachable, but it is because of the inner deadness, engendered through maternal unavailability, that the world appears filled with lifeless things. The first piece of 'furniture' was the absent mother (in the 
infant's eyes) and, in her eyes, the infant. The child takes this relationship into itself, beginning the death of love. The risks implicit in hope, in the wish to communicate are immense, and the need to be loved, and to love, is easily held at bay by a fear of re-traumatization. If there is no world but that of 'furniture', one has nothing to regret, there is no real loss. In such a world, one must be alone, either hopelessly misunderstood: '[our] speech and action are distorted and emptied of their meaning by an intelligence that is not ours', or enacting a falseself: 'we speak and act for others - in which case we speak and act a lie' (47). These are the two poles of Beckett's despair: the loss of the self either by abandonment to an unempathic world, or by a forced compliance, a capitulation. In this, one finds the final cause of selfestrangement and disconnection from authenticity: 'One lies all one's life long ... especially to those that love one, and above all to that stranger whose contempt would cause one most pain - oneself' (47). This quotation, from Proust, demonstrates the damage to the core self created by the sense that the other's love is either dangerous or unavailable, and that self-deception is the only means to survive.

Therefore, for Beckett's Proust, isolation is rationalized, made appropriate. Resignation rules, withdrawal is accepted as inevitable; loneliness and disconnection are held at bay, for the moment: 'the artist is active, but negatively, shrinking from the nullity of extracircumferential phenomenon, drawn into the core of the eddy [...] we are alone. We cannot know and we cannot be known. 'Man is the creature that cannot come forth from himself, who knows others only in himself, and who, if he asserts the contrary, lies' (48-49). Like Sam and Watt, who come together, only for a moment, before forever parting, Beckett and Proust come together here. In his sharing of a deeply held understanding with an artist he admires, Beckett, in a way, undermines his whole thesis. For Proust's art held a profound communication for Beckett, a shared state of loneliness and fragmentation, which was clearly important for him. Perhaps it was this deeply felt experience of understanding Proust and, in a sense, of being understood by Proust, that helped lay a foundation for Beckett's own artistic exploration of an internal state where one is indeed alone, almost entirely without hope, where to hope for love and understanding would be to lie. Hope would contravene a law of nature for the Beckettian narrative-self, though it hides within the texts, within the primal text-making, waiting for an auditor. Yet, the myth must remain, there is no one beyond the self, at least no one who will respond with an empathic understanding and 
with love; there cannot ever be, for she who would have allowed for such a feeling was never felt as being there.

\section{Notes}

1 Material from a number of general references has been helpful in developing parts of this section: Laplanche and Pontalis, 1988; Moore and Fine, 1990, 1995; Bacal and Newman, 1990; Summers, 1994; Hinshelwood, 1991; and Rycroft, 1988.

2 Early in her career Klein suggested, following Freud, that the ego's first act was to deflect outwards (project) the death instinct, and to subsequently face the difficulties of introjecting a now poisoned and dangerous world. The death instinct is a highly problematic concept in psychoanalysis, but is one that could be applied to Beckett's work. I have tended not to speak of it in the study, preferring to view the continual struggle to remain alive as a consequence of a feeling of internal disconnection from a primary object.

3 Freud felt primary-process thinking was his greatest discovery. It uses condensation (the combination of two or more images to form a composite, which is invested with meaning from both) and displacement (the shifting of interest from one image, thought, or object to another). Thus, images can become fused and readily replace or symbolize one another. Within primary-process thinking, there is no concept of space or time, and there can be the use of hallucination to fulfil needs.

4 Simon (1988) and Brink (1982: 87-100) examine Endgame in terms of schizoid object relations.

5 Citing the work of André Green, Baker (1998) explores the introjection of the 'dead mother' in Beckett.

6 See Meares (1986: 545-9) for a discussion of the sense of possession.

7 For some recent thinking, debate, and criticism of the concept see Sandler, 1987, Grotstein, 1985, and Ogden, 1993.

8 Karin Stephen first used the term 'nameless dread' to refer to early infantile anxieties centered on 'a dread of powerlessness in the face of instinct tension' (Stephen, 1941: 178-90).

9 Kohut felt that a vital part of the self was a grandiose aspect that required admiration. The mother (or other caregiver) provided this function to help the development of the self (Kohut, 1971). For general criticisms of concepts of mirroring, see Stern (1985: 144-5), who develops more sophisticated terminology based on infant research. Since I am not attempting to tie Beckett's literature to any specific psychoanalytical theory, I use the term to reflect the importance of maternal recognition of the child in the general sense outlined above.

10 There are clearly religious references in the piece, and I do not mean to suggest that my interpretation is definitive. The images of the closing doors may have been those referred to in a conversation between Beckett and the playwright Israel Schenker. Schenker relates how he spoke sadly to Beckett of his realization that an image he had used in some recent writing, of a door closing, had been accidentally borrowed from Beckett's writing. Beckett, according to 
Schenker, pondered gently, and then said: 'Shit, I stole it from Dante m'self!' (Waiting for Beckett, BBC television, 1995, dir. John Reilly)

11 There are echoes of this in many places; in Godot, for example, the sending of the Boy functions as an opening door, and can be viewed both as sadistic, as well as kindly.

12 In this light, various 'expulsions' in Beckett (e.g. in 'The Expelled', Watt, and so forth) take on a certain meaning - there is a rejection by the inner world of the containing mother (within the self) and an expulsion into a rejecting, external world-mother.

13 Schmideberg reported the importance of clothing in serving a containing function for the child, and clothes serving such a function for a number of Beckettian characters, for whom clothes provide a shielding and containing function (Schmideberg, 1934: 245-64).

14 The sense of 'puzzlement' that engulfs the birds in this state of maternal disconnection can be seen in the tramps' confusion in Waiting for Godot, or in Watt's regression in Watt. It also often acts as a defence against overwhelming feelings of rage.

15 A patient brought this poem into analysis following the analyst's vacation. It was connected (by the patient) to a university lecturer who had discussed it in a class the patient had attended years before, whose nickname among the students was Dr Death (for his allegedly grim demeanour). It was only after the session had ended that the patient realized that he had experienced sadness during the analyst's silence in the session. He related this, in a later session, to a feeling of emotional starvation and internal death during the analyst's vacation.

16 See Kohut (1977: 181-2) for a self-psychological discussion of this Proustian search for a reparative maternal object.

17 Morrison (1982, 349-54) sees the speaker's story as a displacement from his own experience, which he cannot own, and that the 'rip' word reflects his evasion. I suggest the speaker is an aspect of the self that speaks of its own self-state in the monologue. The reason for the displacement is also evident in the sense of primary 'ripping' from the internal good mother. The 'ripping' also suggests the raging infantile response to the disconnection (much like Murphy's raging attack, see below), as well as its fear that the mother will respond violently. 